\title{
Impact Damage to Composite Laminates: Effect of Impact Location
}

\author{
A. Malhotra • F. J. Guild
}

Received: 8 November 2013 / Accepted: 18 December 2013 /Published online: 18 January 2014

(C) The Author(s) 2014. This article is published with open access at Springerlink.com

\begin{abstract}
Accidental impact loading of Composite laminates during manufacture and inservice can occur in different locations including near the edge or on the edge of a composite structure. This paper describes investigation of the effect of impact to composite laminates and compares the damage arising from central, near edge and on edge impact events. The damage tolerance of impact damaged laminates using both compression and tension tests has been measured. These results reveal the different damage mechanisms arising from different locations of impact. These different damage mechanisms have been investigated using XRay computed tomography. Impact on the edge of composite laminates is found to lead to smaller damage area, but more fibre failure; the severity of this damage is not revealed in standard compression after impact tests.
\end{abstract}

Keywords Composite laminates · Edge impact · Damage tolerance $\cdot$

$\mathrm{X}$-Ray computed tomography

\section{Introduction}

In the last decade, researchers in academia and industry have studied extensively the effects of impact damage on the damage tolerance of composite structures and this damage has been shown to introduce several design problems. Excellent overviews of this subject can be found in reviews by Abrate [1,2] and Cantwell and Morton [3-5]. The risk of having a composites structure operating with undetected damage, severely reducing its capacities, makes it necessary to consider the presence of the damage already at the design stage. Although there is much published work on centre impact of thin composite laminates, typically 2 or $3 \mathrm{~mm}$ thick, only a

A. Malhotra F. J. Guild

Department of Materials, Queen Mary University of London, London E1 4NS, UK

Present Address:

A. Malhotra

GKN Aerospace, East Cowes, Isle of Wight PO32 6RA, UK

Present Address:

F. J. Guild $(\bowtie)$

Department of Mechanical Engineering, Imperial College London, London SW7 2AZ, UK

e-mail: F.Guild@imperial.ac.uk 
few recent papers were found on edge impact of laminates, near the edge or on the edge, which may introduce more severe damage [6, 7]. Accidental impact loading of various kinds during manufacture and in-service can occur near the edge or on the edge of a composite structure.

For central impact of composite laminates, good correlation has been found between the incident impact energy and damage initiation and propagation of glass fibre composites at various energy levels [8]; the importance of laminate thickness [9, 10] and stacking sequence [11] has been shown. This paper includes investigation of the impact and damage tolerance of composite laminates subjected to edge impact both near the edge and on the edge. Previous work has included modelling and experimental investigations of composite laminates subjected to near edge impact [12].

The composite plates were subject to low velocity impact at different locations, as indicated in Fig. 1, and at different energy levels. After the impact tests, the residual strength of the plates was measured in compression and tension. The damage has been observed using X-ray computed tomography. The effect of impact position for low velocity impact response and its correlation with residual strength is explored.

\section{Experimental Measurements}

\subsection{Materials}

Vacuum assisted resin transfer moulding technique was used to manufacture the glass fibre reinforced epoxy laminates. Quasi-isotropic glass fibre cloth Cotech EQX 1034 style 3200, non-crimped fibres and non-stitched lay-up, was used. Ply thickness was $0.25 \mathrm{~mm}$. After impregnation, the laminates were left to cure at room temperature for $24 \mathrm{~h}$ and then post- cured at $80{ }^{\circ} \mathrm{C}$ for $7 \mathrm{~h}$. Plates were prepared with thickness $2 \mathrm{~mm}$ and $4 \mathrm{~mm}$, with layups [0/+45/90/ $-45]_{\mathrm{s}}$ and $[0 /+45 / 90 /-45]_{2 \mathrm{~s}}$. The plates were cut using a diamond saw with water-based coolant to $89 \mathrm{~mm}$ length and $55 \mathrm{~mm}$ width.

\subsection{Impact Tests}

Impact tests were carried out using a CEATIS Dartvis 6790 drop-weight impact testing machine, with data acquisition unit DAS4000, which has the capability of 1-MHz sampling rate. The test method has been described in detail elsewhere [12]. The impact machine includes a pneumatic anti-bounce mechanism and force-time data is recorded from the piezoelectric dart striker. The velocity of impact is measured using a triggered photocell. The impactor mass was constant, $0.740 \mathrm{~kg}$, with variable height and therefore velocity of impact to produce the correct incident energy; tests were carried out for five different incident energy levels: 1,2,3,4 and $5 \mathrm{~J}$. The shape of the tup for the central and near edge impact was hemispherical, with radius $7 \mathrm{~mm}$. For the on edge impact a rod-shape tup of length $15 \mathrm{~mm}$ was used to ensure consistent contact across the edge.

The boundary conditions and constraints used for the central impact and two types of edge impact are shown in Fig. 2. For the central impact, the plate was fully constrained around a
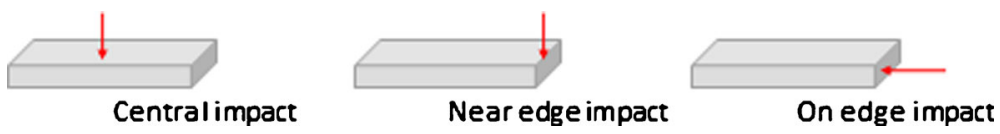

Fig. 1 Different impact locations 
Central

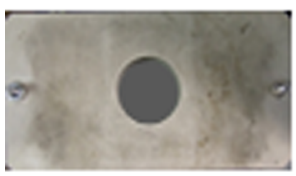

Near edge

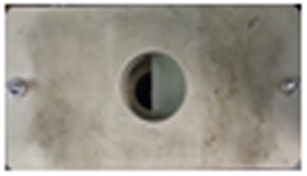

Onedge

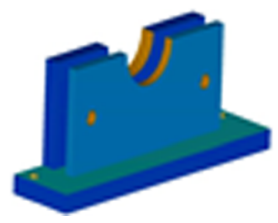

Fig. 2 Boundary conditions for the impact tests

half-circle window of radius $20 \mathrm{~mm}$, with the impact centred. For the near edge impact, the same fixture was used with a free edge exposed along the diameter of the circle. The same boundary conditions were used for the on edge impact with the plate clamped in the fixture shown in Fig. 2. All tests were carried out at ambient temperature, 22 to $24{ }^{\circ} \mathrm{C}$. Three tests were carried out for each condition and good reproducibility was found.

\subsection{Post-Impact Strength Measurements}

Post-impact strength measurements in compression and tension were carried out. The objective of this testing was to test the hypothesis that the different modes of testing would reveal the different failure mechanisms that had occurred for the different impact locations. This hypothesis is illustrated in Fig. 3; compression testing is expected to be more sensitive to delamination, while tension testing is expected to be more sensitive to fibre failure.

\subsubsection{Compression After Impact}

Compression after impact (CAI) testing of the impacted specimens was conducted in order to investigate strength reduction after impact damage. Various methods for CAI test rigs have

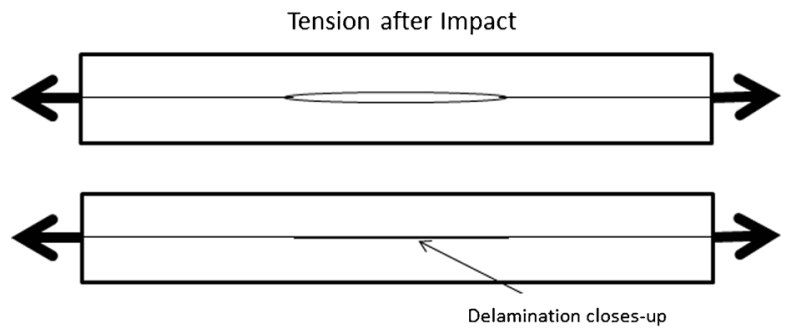

Compression after Impact
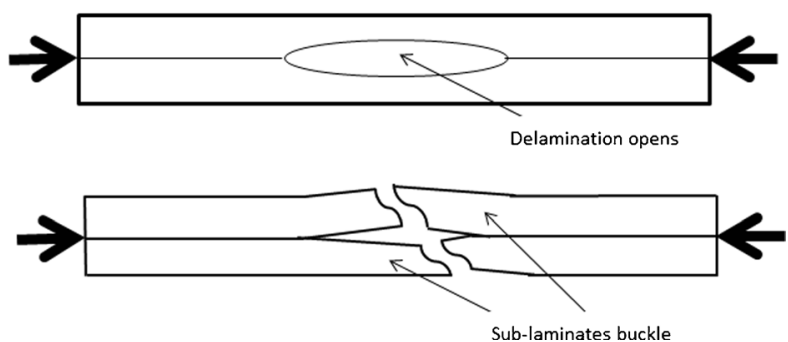

Fig. 3 Damaged composite laminate response in tension and compression 
been developed in the past by several companies for performing compression after impact. CAI designs have been developed by companies including NASA, Boeing, SACMA, Airbus, CRAG [13-15]. Previous research work involved compression after impact centrally on the face of composite laminates [16]. The QMUL fixture developed by Pritchard and Hogg [16] was used and further developed for testing after edge impact. The rectangular specimen was clamped top and bottom and buckling guides were used along the edges. For the central impact, the damage was located at the centre of the specimen, with buckling guides along both edges. For the near edge and on edge impact the damage was located on a free edge of the specimen, with buckling guides along the other edge. An Instron 6025 mechanical test machine with a load cell of $100 \mathrm{kN}$ was used with crosshead speed of $0.5 \mathrm{~mm} / \mathrm{min}$. Three non-impacted specimens were also tested to determine the reduction in residual strength due to the damage produced by impact. Results for damaged plates are presented as normalised values with respect to the undamaged strength.

\subsubsection{Tension After Impact}

Tension after impact (TAI) testing of the impacted specimens was conducted in order to investigate residual tensile strength after impact damage, using the same Instron 6025 mechanical test machine with a $100 \mathrm{kN}$ load cell and crosshead speed of $0.1 \mathrm{~mm} / \mathrm{min}$. The specimen width was reduced to $25 \mathrm{~mm}$, leaving the damaged zone unconstrained centrally along an edge for near edge and on edge impact, but centrally on the specimen face for central impact. Steel end tabs, of $27.5 \mathrm{~mm}$ length were bonded to the specimen with an epoxy resin. Results for undamaged laminate were hard to measure due to specimen slipping. However, two successful test results were obtained for both $2 \mathrm{~mm}$ and $4 \mathrm{~mm}$ thick laminates, and these results have been used to normalise the results for the damaged specimens.

\section{X-Ray Computed Tomography}

X-Ray computed tomography has been used to investigate the different failure mechanisms for the near edge and on edge impacted specimens. The X-ray source was a Sky Scan 1072 Desktop X-Ray microscanner. For maximum contrast the power settings used were $40 \mathrm{kV}$ at $200 \mu \mathrm{A}$. Three-dimensional images have been produced from series of two-dimensional images using the Drishti open-source exploration volume and presentation tool [17]. The specimen width was reduced to $10 \mathrm{~mm}$ for insertion into the specimen holder. The damaged area was positioned at the centre where the scale could be magnified. Post-processing of the images allows either fibres or matrix to be rendered invisible due to their different absorption coefficients. Matrix damage can be highlighted since the absorption coefficient of damaged matrix can be distinguished from that of undamaged matrix.

\section{Impact Test Results}

\subsection{Effect of Thickness and Energy Level}

The effect of incident energy on impact response for near-edge and on-edge impact has been fully described elsewhere [12]. Values of peak force for on edge impact are all around twice the values for near edge impact; values of normalised energy absorbed are similar. All values of both peak force and normalised energy absorbed increase for increasing incident energy, with 
lower values for the thinner laminate. The values of normalised energy absorbed for the two thicknesses tend to coincide at higher incident energy. The damage width for the thinner laminate was found to be larger than the width for the thicker laminate but the difference is smaller for the near edge impact at high values of incident energy.

\subsection{Effect of Impact Location}

The effect of laminate thickness and energy level on force/time and displacement/time response for near-edge and on edge impact has been fully described elsewhere [12]. The responses for central impact are very similar to the near edge impact, with some vibrations found in the force/time response for the near edge impact which did not occur for the central impact. The results are summarised in Fig. 4 for the $4 \mathrm{~mm}$ thick laminate subjected to $4 \mathrm{~J}$ impact. The maximum force and values of energy absorbed, normalised with respect to the energy input, are compared for the three impact locations. The value of maximum force for near edge impact is almost identical to the result for central impact. Higher maximum force is recorded for the on edge impact, as expected due to the greater stiffness of the plate on its edge. The energy absorbed is highest for the central impact and lowest for the on edge impact; this probably arises from the larger area of deformation around the central impact.

\section{Observations of Damage Using X-Ray Computed Tomography}

The X-Ray computed tomography results allow comparison of the amount of fibre fracture and the extent of matrix damage for near edge and on edge impact. The fibre fracture is compared in Fig. 5. These results are both for the $4 \mathrm{~J}$ impact on $2 \mathrm{~mm}$ thick laminate. For the near edge impact (Fig. 5a), fibre fracture is observed for the top $0^{\circ}$ ply for the two tows nearest the edge. For the on edge impact (Fig. 5b), fibre fracture is observed through the entire thickness at the point of impact. Further fibre fractures in the $45^{\circ}$ plies are observed throughout the area of examination. The amount of fibre fracture is far higher for the on edge impact.

The matrix damage is compared in Fig. 6. The results for the on edge impact are for the same thickness $(2 \mathrm{~mm})$ and same impact energy $(4 \mathrm{~J})$ as shown in Fig. 5. However, the results for the near edge impact are for the thicker laminate $(4 \mathrm{~mm})$ and lower impact energy $(2 \mathrm{~J})$ since these results produced the better contrast. Matrix damage for the on edge impact is

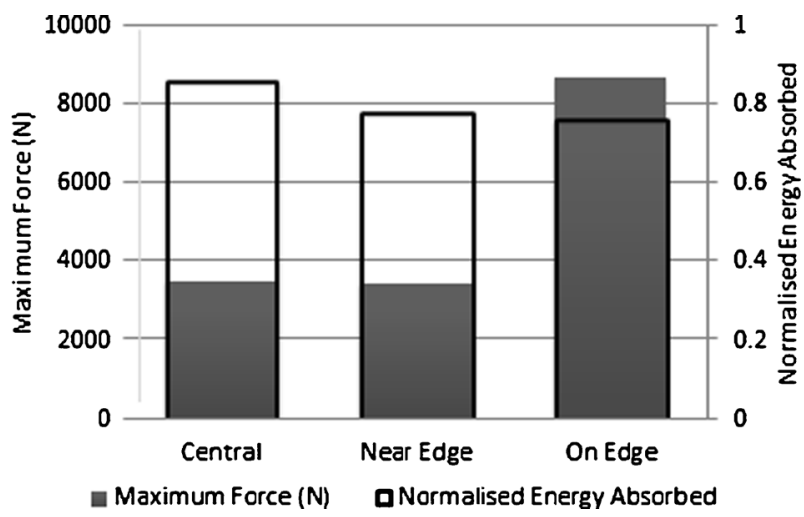

Fig. 4 Variation of maximum force and normalised energy absorbed for different impact locations (4 mm plate; $4 \mathrm{~J}$ impact energy) 
a

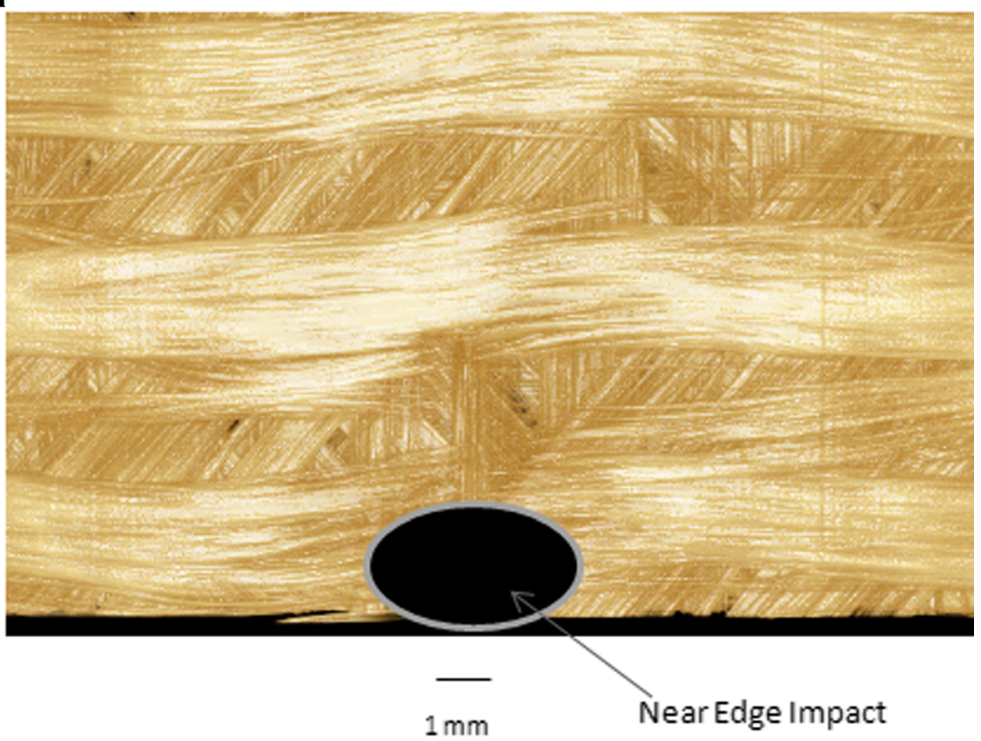

b

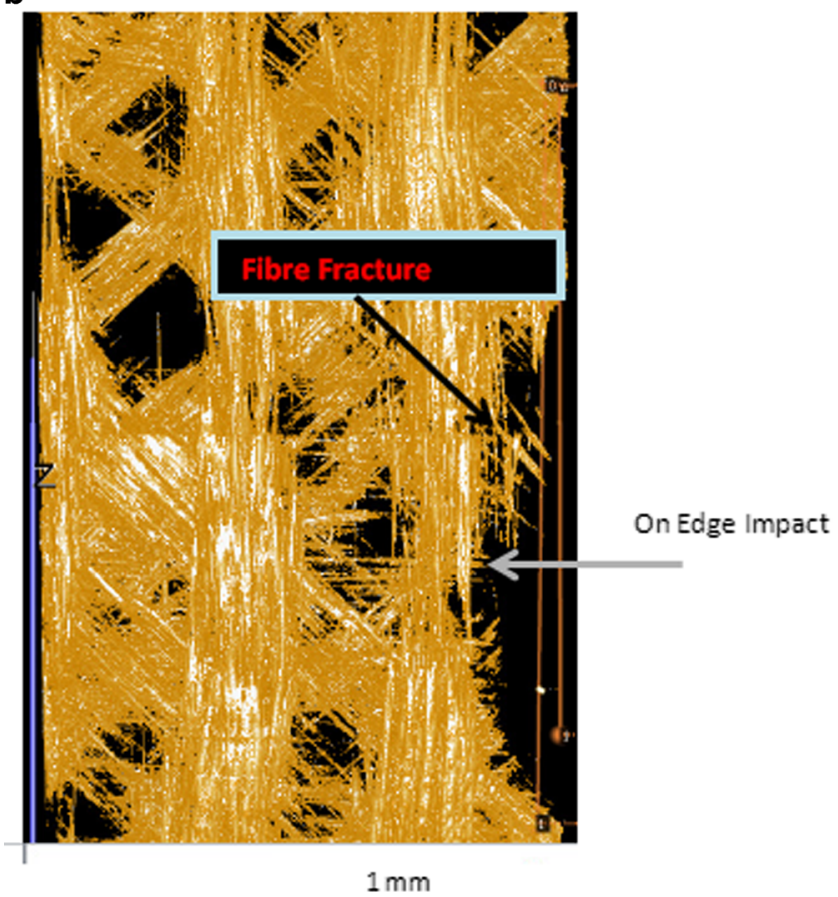

Fig. 5 Fibre damage observed in X-Ray computed tomography. a near edge impact (4 J impact $2 \mathrm{~mm}$ thick) b on edge impact (4 $\mathrm{J}$ impact $2 \mathrm{~mm}$ thick)

confined to a small area around the point of impact (Fig. 6b). Matrix damage for the near edge impact is observed throughout the area of examination (Fig. 6a). This matrix damage leads to the growth of delaminations. The amount of matrix damage is far higher for the near edge impact. 

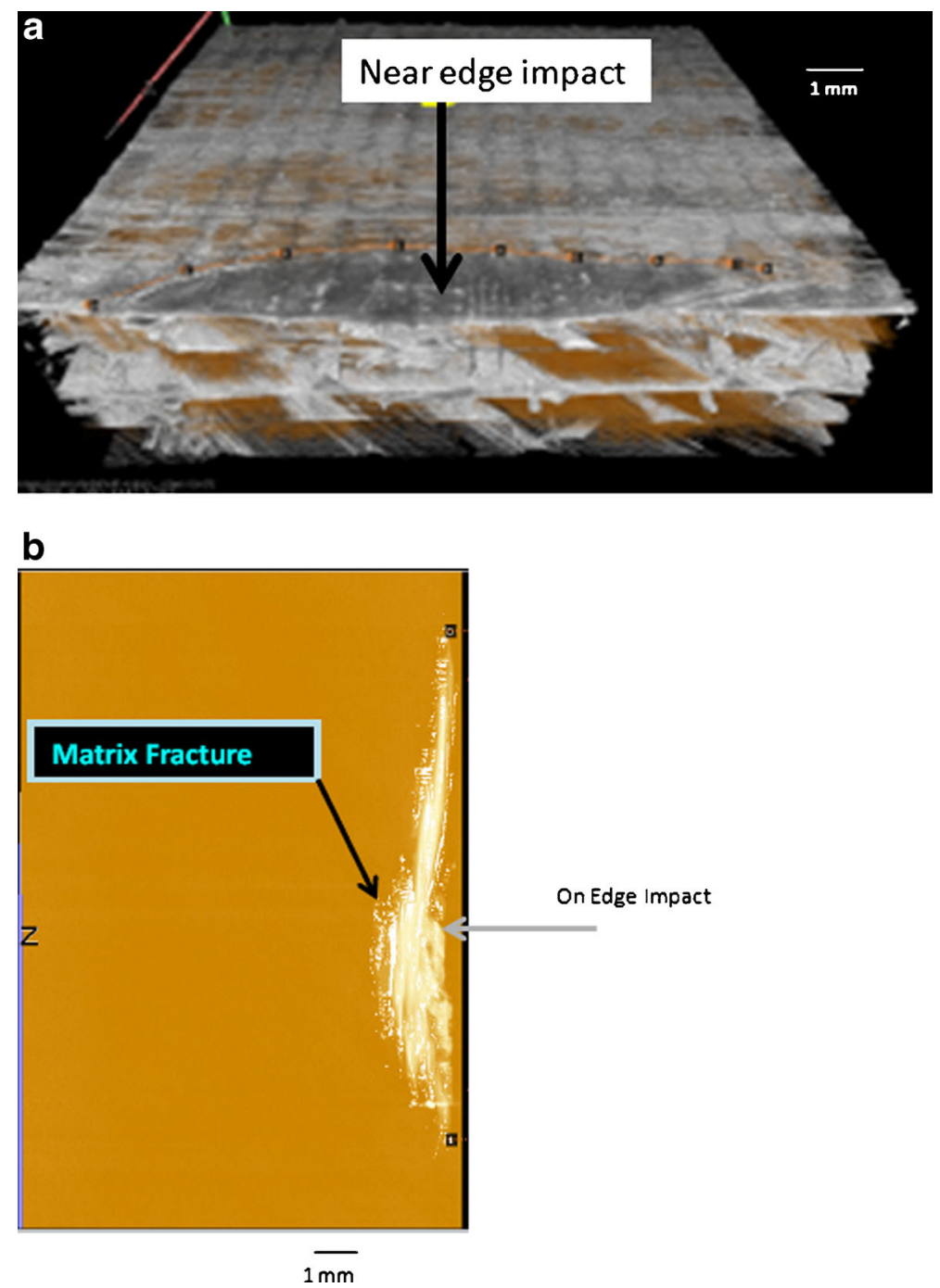

Fig. 6 Matrix damage observed in X-Ray computed tomography. a near edge impact (4 J impact $2 \mathrm{~mm}$ thick) b on edge impact ( $2 \mathrm{~J}$ impact $4 \mathrm{~mm}$ thick)

\section{Post-Impact Strength Tests}

\subsection{Compression After Impact}

The variation of maximum compressive strength in the CAI test for the different impact positions as a function of impact energy are shown in Fig. 7. These are the results for the $4 \mathrm{~mm}$ thick plate; results for the $2 \mathrm{~mm}$ thick plate show similar trends. The compressive strength reduces for increased impact energy for all impact positions, but the decrease is much smaller for the on edge impact. At low impact energies, the compressive strength is similar for all impact positions.

The failure processes in the CAI tests can be deduced from observation of the failed laminates in Fig. 8. Failure appears to have occurred after the damage zone, initiated at the 


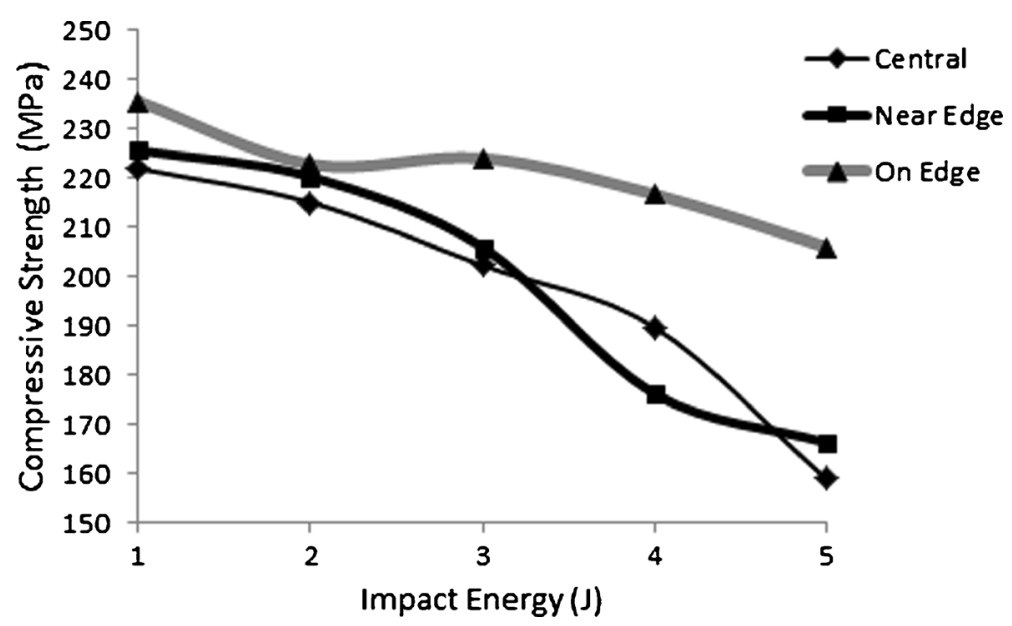

Fig. 7 Variation of maximum compressive strength in the CAI test with impact energy (4 mm thick)

impact location, has grown across the laminate. The damage zone growth for near edge and on edge impact appears similar.
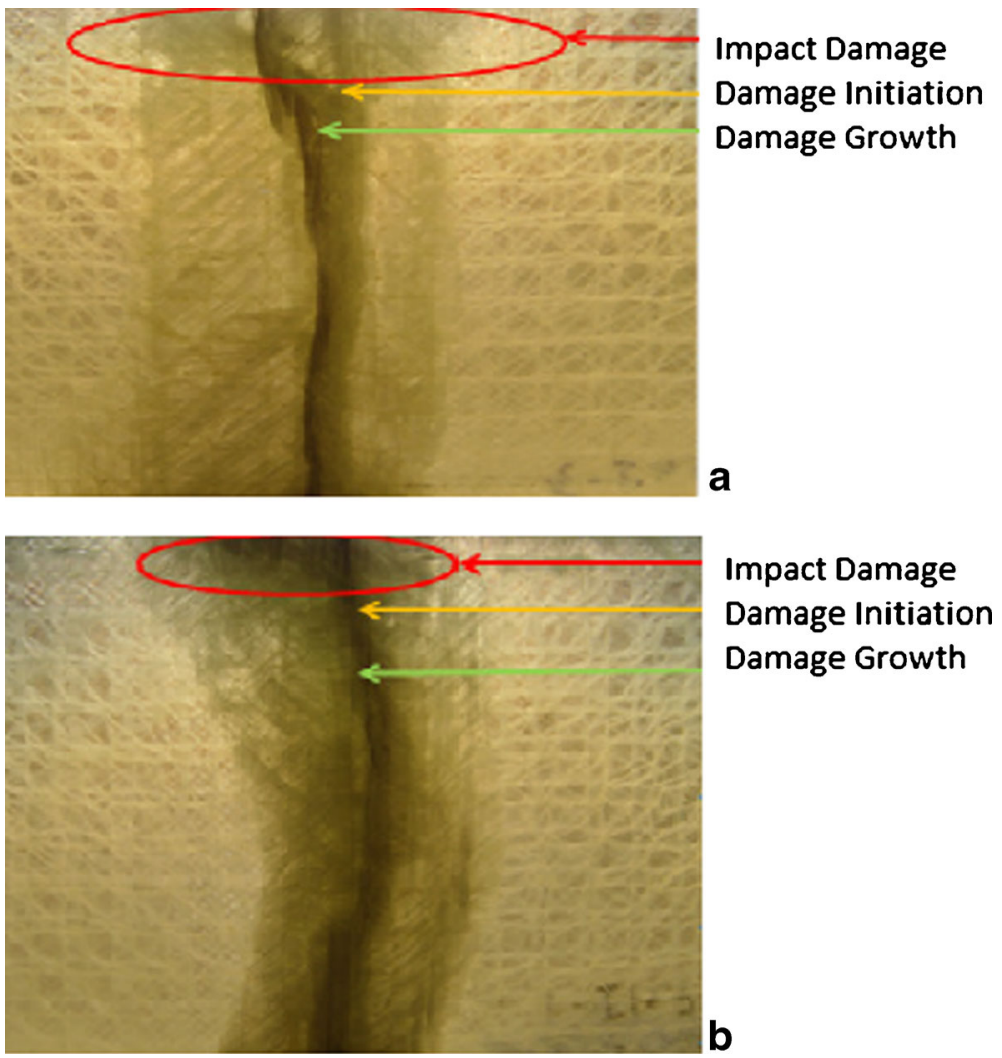

Fig. 8 Damage zone growth in the CAI test. a near edge impact (4 mm thick) b on edge impact (4 mm thick) 


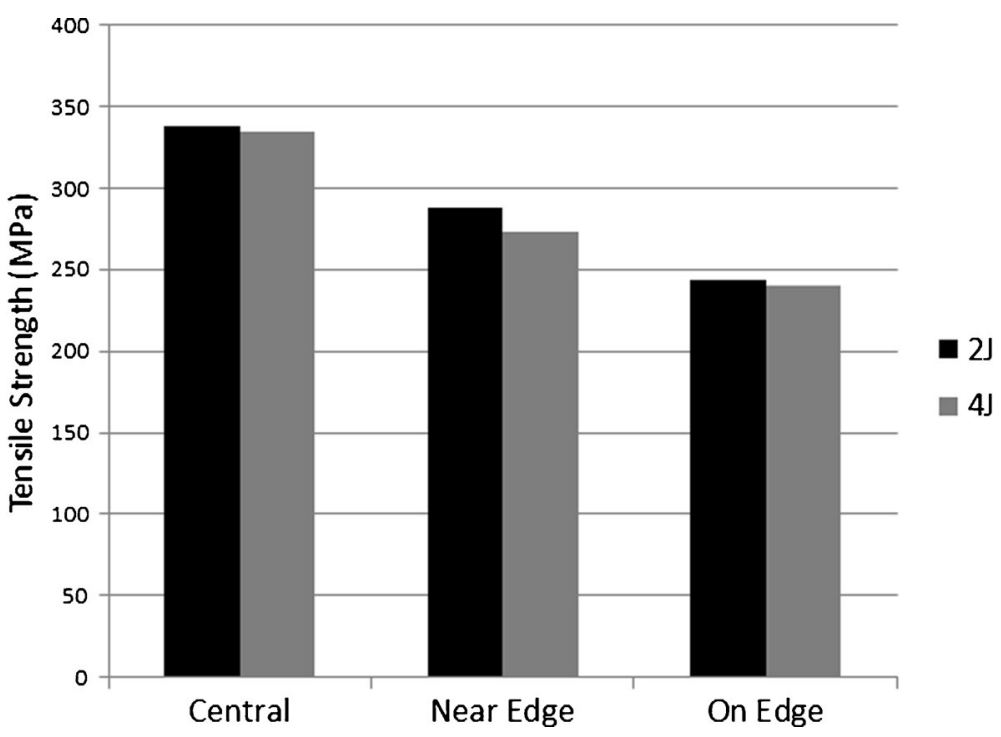

Fig. 9 Variation of maximum tensile strength measured in the TAI test with impact energy (4 mm thick)

\subsection{Tension After Impact}

The variation of maximum strength in the TAI tests for the different impact positions for the two values of impact energy tested are shown in Fig. 9. Some variation with energy level is found for near edge impact, but the strength for both energy levels is very similar for central and on edge impact. For both energy levels, the values of tensile strength are highest for the central impact and lowest for the on edge impact.

The failure processes in the TAI tests can be deduced from observation of the failed laminates shown in Fig. 10. For both near edge and on edge impact, a damage zone appears to have grown from the impact area. The area of delamination around the damage zone appears to be greater for the near edge impact.

\subsection{Comparison of Results from CAI and TAI Tests}

Results for CAI tests and TAI tests are compared using normalised values of maximum load, normalised with respect to the maximum load values for the undamaged laminates. The effect of thickness is summarised in Fig. 11; results are presented for the $4 \mathrm{~J}$ impact. Lower damage tolerance is found for the thicker laminate for the compression test, but higher damage tolerance is found for the thicker laminate for the tension test. The effect of thickness for on edge impact in the compression test is very small. The effect of impact energy is summarised in Fig. 12; results are presented for the $4 \mathrm{~mm}$ thick laminate. Lower damage tolerance is found for higher energy impact for the compression test for all impact positions. The damage tolerance measured in tension is similar at both energy levels for the tension test for all impact positions.

The effect of impact position is shown in Fig. 13; these are the results after $4 \mathrm{~J}$ impact. Similar trends are shown for both values of laminate thickness. For the compression tests, lowest damage tolerance is found for the near edge impact; higher damage tolerance is found for on edge impact, and for the thicker laminate the damage tolerance is significantly higher than for the central impact. For the tension tests, the lowest damage tolerance is found for the on edge impact and the highest 


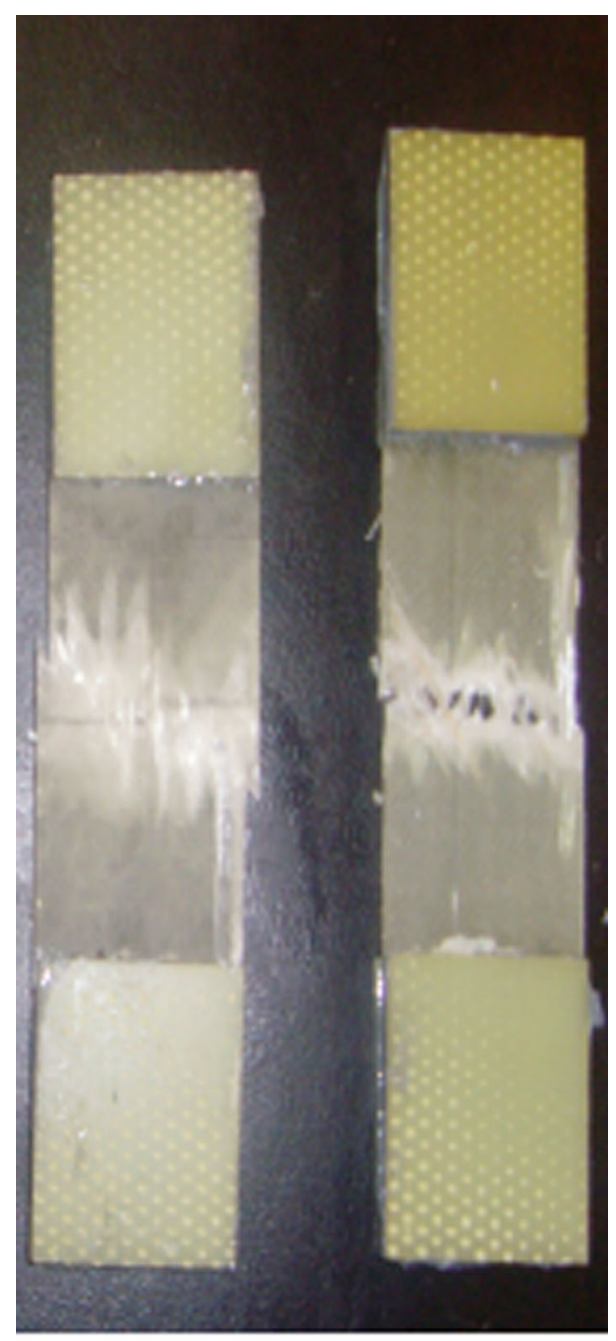

a

b

Fig. 10 Damage zone growth in the TAI test . a near edge impact (4 mm thick) b on edge impact (4 mm thick)

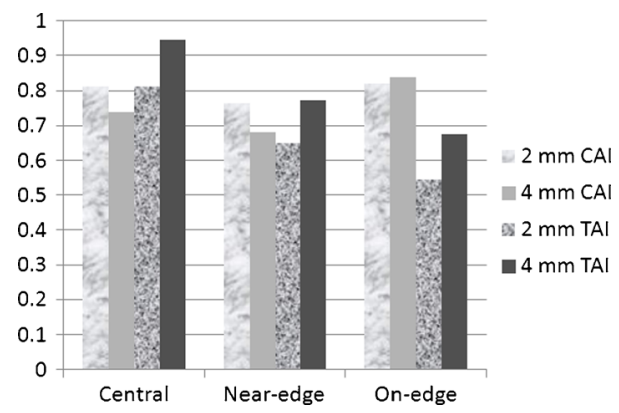

Fig. 11 Effect of thickness in the CAI and TAI tests (Values of strength normalised with respect to undamaged laminates) (4 J impact) 


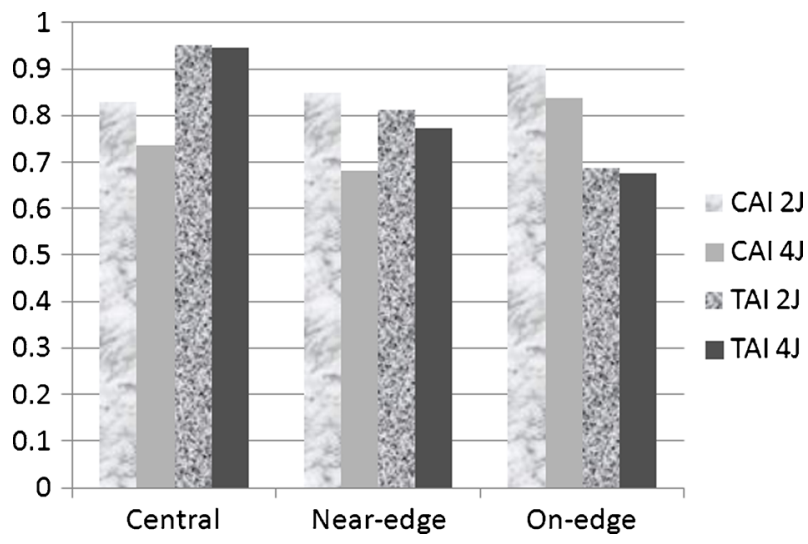

Fig. 12 Effect of impact energy in the CAI and TAI tests (Values of strength normalised with respect to undamaged laminates) (4 $\mathrm{mm}$ thick)

damage tolerance is found for the central impact. The trends are identical for both thicknesses of the laminate, with all values of damage tolerance being higher for the thicker laminate.

\section{Discussion}

Both the impact tests and the subsequent damage tolerance tests in compression and tension have been compared for the three impact locations (see Fig. 1). The impact responses from the
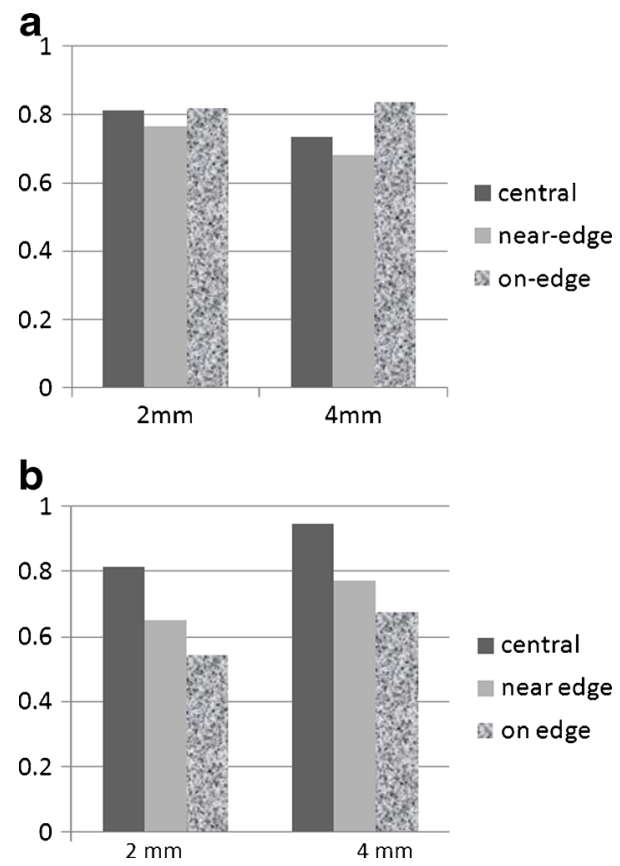

Fig. 13 Effect of impact location in the a CAI and $\mathbf{b}$ TAI tests (Values of strength normalised with respect to undamaged laminates) (4 J impact) 
central and near edge impacts are very similar except that more energy is absorbed for the central impact. This is not surprising since the surrounding laminate area of deformation and damage for the central impact is twice that surrounding the near edge impact. The impact response from on edge impact show higher maximum load and far shorter impact time; the plate on its edge is stiffer as expected.

Previous work has included optical inspection of the impact damage [12]; delaminations and fibre failure were observed for both near edge and on edge impact, with evidence of greater delamination area for the near edge impact and more fibre failure for the on edge impact. These further investigations of the impact damage using X-ray computed tomography have confirmed the previous observations. The damage arising from on edge impact is less widespread than the damage arising from impacts on the plane of the laminate. The results from the X-Ray Computed Tomography show that fibre failure occurs for both near edge and on edge impact, but the extent of the fibre failure is far greater for the on edge impact. Damage from impacts on the plane of the laminate is dominated by delamination, with fibre failure only found in the top plies under the impactor.

The presence of delaminations is expected to be well detected in compression after impact tests. This is confirmed in this work (see Fig. 13a) which confirms the lower damage tolerance arising from near edge impact which has been explored in previous work [6]. The damage tolerance of the on edge impact is measured as the same or higher than central impact for the compression test. These results indicate that maximum delamination length arises from near edge impact and minimum delamination length arises in on edge impact.

In contrast to the compression after impact test, results for the tension after impact show clear trends (see Fig. 13b). Significantly lower damage tolerance is found for the on edge impact. This must arise from the domination of fibre failure that occurs for on edge impact. Delaminations are not expected to influence damage tolerance in tension (see Fig. 3), so these results indicate that near edge impact leads to more fibre failure than central impact.

The failure processes in CAI and TAI tests appear similar, with damage zone growth from the impact location for both near edge and on edge impacts. For the TAI tests, there is some evidence of more delamination around the damage zone for the near edge impacted laminate compared to the on edge impacted laminate. The strength of the laminate must be related to the stress required for the initiation of this damage zone. Comparing the values of compressive and tensile strength (Figs. 7 and 9); values for on edge impact are similar while tensile values for near edge and central impact are all higher, the difference being greater for central impact. Comparing results from the different types of impact and different tests (Figs. 13a and b), this value of initiation stress appears to be lower in compression when more delamination is present, but lower in tension when more fibre failure is present.

Damage tolerance measured using compression-after-impact tests is the widely accepted standard. This method is robust in detection of delamination damage, which is difficult to detect and can lead to premature failure. However, fibre failure can also lead to catastrophic failure, particularly as the precursor to growth of fatigue failures. These results have shown that the extent of fibre failure is not readily detected in conventional compression after impact tests, and is the main damage arising from on edge impact. Since accidental low velocity edge impacts can accidentally occur both during composite manufacture and service, this is an important observation. 


\section{Concluding Remarks}

Impact tests on composite laminates have been carried out at three different locations. The impact response arising from on edge impact was found to be very different from impacts on the plane of the laminate. These observations were successfully explored using X-ray computed tomography. The different failure mechanisms were highlighted from comparison of results from compression after impact and tension after impact tests. Damaging fibre failure, caused by accidental low velocity impact on the edge of a composite laminate, is not readily detected in conventional compression after impact tests.

Acknowledgments The authors thank Dr Graham Davis, Institute of Dentistry, Queen Mary, University of London for his invaluable assistance and discussions regarding the X-ray computed tomography measurements. We gratefully acknowledge useful discussions with Professor Martyn Pavier, University of Bristol. We thank Dr K. Berketis, Dr C Jeenjitkaew and Mr Bill Godwin, Queen Mary, University of London, for their invaluable discussions and technical help.

Open Access This article is distributed under the terms of the Creative Commons Attribution License which permits any use, distribution, and reproduction in any medium, provided the original author(s) and the source are credited.

\section{References}

1. Abrate, S.: Impact of laminated composite materials: a review. Appl. Mech. Rev. 44, 155-189 (1991)

2. Abrate, S.: Impact of laminated composites: recent advances. Appl. Mech. Rev. 47, 517-544 (1994)

3. Cantwell, W.J., Morton, J.: Geometrical effects in the low velocity response of CFRP. Compos. Struct. 1, 39-60 (1989)

4. Cantwell, W.J., Morton, J.: An assessment of the residual strength of an impact-damaged carbon fibre reinforced epoxy. Compos. Struct. 14, 303-317 (1990)

5. Cantwell, W.J., Morton, J.: The impact resistance of composite materials: a review. Compos. 22, 347-362 (1991)

6. Breen, C., Guild, F.J., Pavier, M.J.: Impact damage to thick carbon fibre reinforced plastic composite laminate. J. Mater. Sci. 41, 6718-6724 (2006)

7. Rhead, A.T., Marchant, D., Butler, R.: Compressive strength of composite laminates following free edge impact. Compos. A41, 1056-1065 (2010)

8. Zhou, G.: Damage mechanisms in composite laminates impacted by a flat-ended impactor. Compos. Sci. Technol. 54, 267-273 (1995)

9. Morais, W.A., Monteiro, S.N., d'Almeida, J.R.M.: Effect of the laminate thickness on the composite strength to repeated low energy impacts. Compos. Struct. 70, 307-315 (2005)

10. Sutherland, L.S., Guedes Soares, C.: Effect of laminate thickness and of matrix resin on the impact of low fibre-volume, woven roving E-glass composites. Compos. Sci. Technol. 64, 1691-1700 (2004)

11. Mili, F., Necib, B.: The effect of stacking sequence on the impact-induced damage in cross-ply E-glass/epoxy composite plates. J. Appl. Mech. 79, 1019-1031 (2012)

12. Malhotra, A., Guild, F.J., Pavier, M.J.: Edge impact to composite laminates: experiments and simulations. J. Mater. Sci. 43, 6661-6667 (2008)

13. NASA Reference publication 1092 - Standard tests for toughened resin composites, NASA (1983)

14. Aramah, S.E.: Significance of Damage in Composite Materials. PhD thesis, Queen Mary and Westfield College, University of London (2001)

15. Hodkinson, J.M.: Mechanical testing of advanced fibre composites. Woodhead publishing Ltd and CRC Press (2000)

16. Pritchard, J.C., Hogg, P.J.: The role of impact damage in post-impact compression. Compos. 21, 503-511 (1990)

17. http://sf.anu.edu.au/Vizlab/drishti/ 